\title{
Aspectos de la identidad gallega en Buenos Aires (1900-1960)
}

\author{
Galician identity in Buenos Aires (1900-1960)
}

\author{
Ruy FARÍAS \\ Universidad Autónoma de Entre Ríos / Museo de la Emigración Gallega en la Argentina \\ ruygonzalofarias@yahoo.com.ar
}

[Recibido, setembro 2010; aceptado, setembro 2010]

\section{RESUMEN}

Entre comienzos del siglo XX y 1960 la Argentina fue el más importante de los destinos migratorios gallegos. A través del análisis de la forma en la que las personas que participaron de esa experiencia conservaron, modificaron o perdieron su lengua materna, cultura culinaria y formas de sociabilidad, el trabajo pretende iluminar cómo se preservó la identidad gallega en el contexto de aquella nueva sociedad.

PALABRAS CLAVE: Emigración gallega, siglo XX, Argentina, identidad, integración.

FARÍAS, R., (2011): “Aspectos de la identidad gallega en Buenos Aires (1900-1960)”. Madrygal (Madr), 14: 59-69.

\section{RESUMO}

Entre comezos do século XX e 1960 a Arxentina foi o máis importante dos destinos migratorios galegos. A través da análise da forma na que as persoas que participaron desa experiencia conservaron, modificaron ou perderon a súa lingua materna, cultura culinaria e formas de sociabilidade, o traballo pretende iluminar de que xeito se preservou a identidade galega no contexto daquela nova sociedade.

PALABRAS CHAVE: Emigración galega, século XX, Arxentina, identidade, integración.

FARÍAS, R., (2011): “Aspectos da identidade galega en Bos Aires (1900-1960)”. Madrygal (Madr.), 14: 59-69.

\begin{abstract}
Argentina was the most important migratory destination for Galicians between the beginning of the 20th century and 1960. This work seeks to shed light on the ways Galician identity was preserved in the context of the new social environment. In order to do so, I will analyze the ways in which the protagonists of this experience preserved, modified, or lost their mother tongue, culinary culture and socializing practices.
\end{abstract}

KEY WORDS: Galician migration, $20^{\text {th }}$ century, Argentina, identity, integration.

FARÍAS, R., (2011): “Galician identity in Buenos Aires (1900-1960)”. Madrygal (Madr.), 14: 59-69. 
El fenómeno migratorio constituye, indudablemente, el aspecto más decisivo de la demografía gallega y de la misma Historia del país a lo largo de los siglos XIX y XX. Y de todas las corrientes que partieron a Ultramar, ninguna fue más caudalosa que la que tomó rumbo hacia la Argentina: aunque tópica, la denominación de "quinta provincia" que esta República recibió responde a un hecho muy real. ${ }^{1}$

Si bien de manera forzosamente superficial, en las páginas que siguen abordaremos algunos aspectos relacionados con la identidad de los migrantes gallegos en Buenos Aires entre comienzos del siglo XX y 1960: sus formas de alimentación y sociabilidad, y su relación con la lengua gallega. Partimos de la premisa de que el modo en el que estas personas conservaron, modificaron o perdieron su lengua materna, cultura culinaria y formas de sociabilidad, dice mucho acerca de su identidad (e integración) en la sociedad del litoral pampeano argentino. Mas, dado que en la mayoría de los casos se trata de individuos llegados del medio rural, el trabajo se inicia con el análisis de algunas de las características de la sociabilidad y alimentación propias del campo gallego, de manera que se pueda visualizar mejor el modo en que las mismas se trasplantaron, conservaron, modificaron o desaparecieron en la sociedad de destino.

\section{ALIMENTACIÓN, SOCIABILIDAD Y LENGUAJE EN LA GALICIA RURAL}

\section{Al despuntar el siglo XX, los diferentes grupos}

que componían la sociedad gallega organizaban su convivencia y el consumo de los alimentos de modos diferentes, pudiendo señalarse características distintivas para cada uno de ellos en lo que hace a las pautas de intercambio, locus de sociabilidad y consumo, presentación, distribución e ingesta de los mismos. Siguiendo a Xavier Castro Pérez, ${ }^{2}$ se constata en las zonas rurales gallegas una baja propensión a invitar a personas de fuera de la familia a participar de una comida, resultando evidente que la omnipresente precariedad económica del medio (donde los alimentos escasamente alcanzaban para los miembros de cada unidad habitacional) se halla en la base de esta escasa afición a realizar convites. Por ello, cuando éstos se verificaban podemos estar seguros de hallarnos en presencia de circunstancias excepcionales, pudiendo discriminárselas en dos tipos básicos: las derivadas de las fiestas (la del santo patrón de la parroquia, casamientos, bautismos, etc.), y las generadas por la dinámica de la xeira y tornaxeira (literalmente "don" y "contra-don"), que encarna un sistema socioeconómico de intercambio recíproco de ayuda de trabajo entre el campesinado. En ocasión de estas circunstancias solían realizarse banquetes, a los que sólo se invitaba a los familiares o a casas muy vinculadas, como corresponde a una sociedad en la que la vecindad y el parentesco tenían una importancia superlativa frente a la que se otorgaba a las "relaciones de afinidad electiva", es decir aquellas puramente amistosas, mucho más operativas en el medio urbano. ${ }^{3}$

En los banquetes con los que excepcionalmente se regalaban (en ocasión de los casamientos,

\footnotetext{
${ }^{1}$ Más del $17 \%$ de todos los inmigrantes europeos arribados al país entre 1857 y 1930 pertenecían al colectivo gallego. Y tras la interrupción de los flujos causada por la crisis económica de 1929, la Guerra Civil Española y la Segunda Guerra Mundial, la "última oleada" verificada entre 1946 y 1960 depositó en las costas argentinas, cuando menos, a otros 100.000 inmigrantes galaicos. De tal modo, entre la primera y la última de las fechas indicadas no menos de 600.000 gallegos se radicaron de forma definitiva en la Argentina, una cifra sin duda impresionante, pero que resulta aún más impactante si atendemos al hecho de que, debido a su acusada tendencia a concentrarse en las zonas urbanas del litoral pampeano y-sobretodo-en Buenos Aires, a lo largo de toda la primera mitad del siglo XX vivieron en la capital rioplatense, más gallegos que en ningún otro núcleo urbano del planeta. Para una mirada de conjunto de la Historia gallega a lo largo de las últimas dos centurias, véase VILLARES, Ramón (2004): Historia de Galicia. Vigo: Galaxia. Sobre el fenómeno migratorio producido a lo largo de esos mismos años, VILLARES PAZ, Ramón y FERNÁNDEZ SANTIAGO, Marcelino (1996): Historia da emigración galega a América. Santiago de Compostela: Xunta de Galicia. Para el caso puntual de la inmigración gallega en la Argentina, NÚÑEZ SEIXAS, Xosé Manoel -editor- (2001): La Galicia Austral. La inmigración gallega en la Argentina. Buenos Aires: Biblos; FARÍAS, Ruy -compilador-(2007): Buenos Aires Gallega. Inmigración, pasado y presente. Buenos Aires: Comisión para la Preservación del Patrimonio Histórico Cultural de la Ciudad de Buenos Aires. Desde una posición de menores pretensiones científicas, pero sin duda más amena y emotiva, PÉREZ-PRADO, Antonio (1973): Los gallegos y Buenos Aires. Buenos Aires: Sobre el fenómeno migratorio europeo en el país, DEVOTO, Fernando (2003): Historia de la inmigración en la Argentina. Buenos Aires: Sudamericana.

2 CASTRO PÉREZ, Xavier (2001): Ayunos y yantares. Usos y costumbres en la historia de la alimentación. Madrid: Nivela.

3 El predominio de los vínculos de parentesco y paisanaje se halla en relación directa con el ordenamiento socioeconómico del agro gallego, donde el interés y la presión social motorizaban las ayudas comunitarias a partir de los mencionados vínculos, debiendo prestarse las mismas con independencia de la existencia o no de lazos de amistad entre los individuos (o más bien de las casas implicadas), y bajo la amenaza implícita de que la conducta socialmente "inapropiada" atrajera sobre la casa la sanción social de su aldea o parroquia.
} 
fiestas patronales, etc.), los aldeanos ensayaban un objetivo instrumental que, en la práctica, acercaba estos convites a los fines de aquellas otras comidas que se brindaban por compromiso, como pago de servicios. Todos tenían un carácter pragmático, ya que perseguían la obtención de un cierto capital relacional por parte de quien los ofrecía. En estas ocasiones, frente a la moderación pequeño burguesa y el refinamiento de las clases altas, nos encontramos con el carácter recargado de las comidas de las aldeas campesinas. De igual modo, resalta el contraste entre la escasez que imperaba en las ocasiones ordinarias y lo que sucedía en aquellas reuniones, en las que solía dilapidarse la comida (y el tiempo, que se iba en largas y bulliciosas sobremesas). Si los sectores populares celebraban menos banquetes que aquellos otros más elevados, cuando podían hacerlos, los mismos derivaban en sonadas desmesuras gastronómicas, conducta que nos habla cuando menos, de dos cosas diferentes: por un lado, de una carencia cotidiana real; por el otro, de cierto afán de demostración de status, relacionado con un pretendido ideal de mesa farta, rebosante de comida y bebida, lo que implicaba también un mayor aprecio por la gran cantidad de comida que sobraba, algo de importancia superior incluso a la de los "regios" bocados servidos, porque era ahí -precisamente- donde podía hacerse demostración de lo que se comía (o de lo que se pretendía comer). Sobresale, además, la importancia conferida a la sustancia en relación a la forma. La preeminencia otorgada a la sustancia, incitaba a reivindicar los alimentos reconocidos en el ámbito campesino como más nutritivos y fortificantes, y que solían ser pesados, grasos, salados y fuertes, siendo su paradigma la carne, verdadera antítesis del pescado, conceptuado como ligero e insustancial.

Si volvemos la mirada a otro aspecto de la sociabilidad en la sociedad de partida, resulta obvio que eran las clases altas urbanas y rurales (junto con los estratos superiores de las medias urbanas) las que se encontraban en situación de poder frecuentar los restaurantes, un ámbito en el que reproducían conductas refinadas en relación a la presentación y el consumo de los alimentos. Por el contrario, las clases bajas del campo y la ciudad preferían mantener una relación más disipada y espontánea, marcada asimismo por una gran naturalidad y familiaridad. Ya fuera en la casa o en la taberna (un espacio en el que, conviene aclararlo, las mujeres no tenían cabida), comiendo o bebiendo, solían establecer una relación más desinhibida y franca, confraternizando y dejándose ir, con renuncia a la contención y circunspección de las clases medias, y en completo contraste con el afán de marcar distancias y rodearse del aire de original distinción característico de las superiores. La taberna (o el bar popular) no era sólo un lugar al que se iba a beber, sino que se acudía a él para beber en compañía e instaurar una relación de familiaridad. Era un espacio en el que se bromeaba, murmuraba y también se cantaba.

Un tercer aspecto fundamental de la cultura popular campesina gallega es el de la lengua. Resulta sabido que la situación sociolingüística de Galicia en la primera mitad del siglo XX (aunque no sólo entonces) reviste características singulares, que afectarán de modo significativo la inserción de los futuros migrantes en la sociedad porteña. La gallega constituye un claro ejemplo de sociedad en la que un idioma es considerado como habla de prestigio, culta y superior (lengua "A"), reservándose su uso a los ámbitos oficiales y altamente valorados, mientras otro es tildado de inferior, cargado con el estigma de ser el propio de los labradores incultos, y limitándose su uso a los ámbitos familiares e informales (lengua "B"). En este tipo de conflicto diglósico, el castellano se convirtió en la lengua " $A$ ", empleándosela para el uso "formal" (la escuela, la Iglesia, el aparato del Estado, la escritura, etc.), en tanto el gallego (lengua "B", y objeto de un prejuicio que la minusvaloraba y la hacía sinónimo de ignorancia) se veía confinado al uso en el seno de la familia o el medio rural. ${ }^{4} \mathrm{Si}$ los hablantes de una lengua dominada suelen asumir la ideología de los sectores dominantes, sus prejuicios y valoraciones, llegando ellos mismos a considerar como inferior y signo de ignorancia su lengua (autoodio), es altamente probable que una buena proporción de los inmigrantes galaicos en Buenos Aires asumieran la estigmatización de su idioma materno aún antes de abandonar Galicia, por lo que (anticipando uno de los temas que desarrollaremos más adelante) parte del

\footnotetext{
${ }^{4}$ Un resumen de la situación de diglosia en Galicia, con especial referencia a las décadas de 1940 y 1950, en GUGENBERGER, Eva (2001): "Identidad, conflicto lingüístico y asimilación: observaciones acerca de la lengua gallega en Buenos Aires", en X. M. Núñez Seixas (editor), La Galicia Austral, pp. 252-6.
} 
proceso de asimilación lingüística al castellano pudo haberse desarrollado allí mismo. Con todo, según Xosé Manoel Núñez Seixas, es indudable que a la altura de 1900

entre os emigrantes era maior a taxa de alfabetización en castelán que entre os que en Galicia ficaban. [...]. Mais alfabetización en castelán [...] non significaba necesariamente un grao satisfactorio de competencia lingüistica activa naquela lingua no intre de desembarcar en Bos Aires. De aí que o idioma galego seguise vivo na emigración, sobre todo cando unha alta porcentaxe dos emigrantes voltaba ó cabo de varios anos a Galicia, e as taxas de retorno se achegaban ó cincoenta por cento. ${ }^{5}$

Por otra parte, entre el comienzo del siglo y 1914 (el período álgido de la inmigración gallega en la Argentina) esas tasas de alfabetización descendieron, debido a que la masificación del contingente migratorio permitió la inserción sociolaboral de individuos sin cualificación. De modo que durante buena parte del período que nos ocupa, una amplia proporción de los emigrantes de Galicia que llegaron a las costas platenses continuaban siendo monolingües en gallego. ${ }^{6}$

La conservación de una identidad cultural diferenciada, se verifica (o no) en las pautas de comportamiento cotidianas adoptadas a partir del momento de arribar al nuevo país. Para Xosé Neira Vilas, quien en la década de 1950 fue emigrante en Buenos Aires, nada más adecuado en su discurso de ingreso a la Real Academia Galega (un resumen de la labor cultural gallega en esta ciudad durante aquel decenio) que la enumeración de

algúns aspectos da nosa cultura popular, reveladora do xenio dun pobo que leva a patria consigo mundo adiante e que se insire natural e amorosamente na nova sociedade sen esluirse, sen perder os seus signos diferenciais. ${ }^{7}$

Pero ¿fue realmente así? ¿Conservó en la nue- va sociedad el inmigrante gallego aquellos "signos diferenciales"? En particular ¿qué ocurrió con sus formas de sociabilidad, lengua y hábitos culinarios? Trataremos de aproximarnos a ello en las páginas que siguen.

\section{ELASOCIACIONISMO}

Fueron incontables los inmigrantes galaicos que llegaron a la capital argentina directamente desde sus aldeas, sin haber conocido antes siquiera la capital de su provincia natal. Por ello, el desembarco en la urbe porteña significó también para muchos, su primer contacto con un medio urbano donde conformaron un nuevo grupo étnico dotado de una identidad cultural propia. Si bien no renunciaron concientemente a ella (aunque, como veremos, dicha afirmación no parece aplicable a lo sucedido con su lengua), esa identidad se vio sometida inevitablemente a un proceso de transformación debido al contacto con la sociedad porteña y su cultura, tanto la criolla como la de los otros colectivos inmigrantes que allí se afincaron. Sin duda el patrón de asentamiento adoptado jugó un papel determinante en esta dinámica, pues la evidencia empírica con la que hasta ahora contamos no ha mostrado la existencia de "barrios étnicos" gallegos (al estilo de las little italies características de la emigración italiana en los Estados Unidos), en los que pudieran hallarse segregados del resto de los habitantes del país. Por el contrario, todo lleva a pensar que la norma fue que los inmigrantes de Galicia en la Argentina se integrasen espacialmente con el resto de la población. ${ }^{8}$ Además, a diferencia de lo ocurrido con otros colectivos, por regla general enviaron a sus hijos a la escuela pública. Sin embargo, después de encontrar donde vivir y un modo de ganarse la vida, el paso siguiente en la adaptación del inmigrante consiste en recrear una red social secundaria. Con

${ }^{5}$ NÚÑEZ SEIXAS, Xosé Manoel (2002): O inmigrante imaxinario. Estereotipos, identidades e representacións dos galegos na Arxentina (1880-1940). Santiago de Compostela: Universidade de Santiago de Compostela, pp. 212-3. Las bastardillas pertenecen al autor.

${ }^{6}$ Sobre el grado de instrucción de los emigrantes gallegos y su relación con las condiciones propias del país, véase PEÑA SAAVEDRA, Vicente (1991): Éxodo, organización comunitaria e intervención escolar. La impronta socio-educativa de la emigración transoceánica en Galicia. Santiago de Compostela: Xunta de Galicia, vol I, pp. 167-77.

7 NEIRA VILAS, Xosé (2001): A cultura galega en Buenos Aires: 1950-1960. A Coruña: Real Academia Galega, p. 35.

${ }^{8}$ No obstante, desde el último cuarto del siglo XIX sí existieron algunos casos de importantes concentraciones gallegas en puntos más o menos delimitados, como pueden ser los barrios de Montserrat, San Telmo, Constitución, Barracas o Parque Patricios y, en el vecino municipio de Avellaneda, la ciudad homónima y la localidad de Piñeiro. NÚÑEZ SEIXAS, Xosé Manoel (2007): "Un panorama social de la inmigración gallega en Buenos Aires, 1750-1930”, en R. Farías (compilador), Buenos Aires Gallega, p. 41. 
tal finalidad los gallegos fundaron o se afiliaron a una plétora de asociaciones voluntarias de corte étnico. De este modo, buena parte de su integración en la Argentina tuvo lugar a través de su participación en una colectividad o comunidad emigrante, la cual conforma un espacio de interacción social donde se recrea aquel otro del que proceden sus integrantes. Pero los gallegos no sólo participaron de la vida de las asociaciones panhispánicas, ${ }^{9}$ sino que también crearon un sinnúmero de sociedades de corte puramente galaico.

Las relaciones de paisanaje originadas en la sociedad de partida que articulan las redes sociales dentro de las que, a su vez, se forman las llamadas cadenas migratorias, afectaron muchos niveles de la vida cotidiana de los gallegos en Buenos Aires, sobre todo en los primeros tiempos que siguieron a la llegada a esta ciudad. ${ }^{10}$ Tuvieron, por ejemplo, una importancia superlativa en la búsqueda del primer empleo (es decir, en la inserción socioprofesional), así como también en ulteriores cambios del mismo; otro tanto puede decirse de las tareas relativas a la edificación de la vivienda. Ambos hechos han quedado reflejado en múltiples textos autobiográficos, tanto individuales como colectivos. ${ }^{11}$ Esas mismas relaciones de paisanajes fueron también fundamentales para la aparición de una amplísima red de asociaciones étnicas, en torno a las que se verificó buena parte de la sociabilidad de los inmigrantes gallegos en la ciudad porteña, quienes desarrollaron prácticamente todas las posibilidades de ese tipo de asociacionismo, combinando la procedencia geográfica (regional, provincial, comarcal, municipal o parroquial) con los objetivos que cada institución perseguía (mutualista / médica, beneficencia, cultural, recreativa, deportiva, etc.). Más allá de la actuación sin duda determinante que en su surgimiento cupo a la elite galaica de Buenos Aires (interesada en la promo- ción y el mantenimiento de esas formas asociativas como parte de su "capital simbólico" dentro de la propia comunidad gallega y española emigrada), ${ }^{12}$ es evidente que los inmigrantes gallegos experimentaron un importante choque cultural al momento de desembarcar en la populosa y cosmopolita capital, y que este violento contraste entre la sociedad de partida y la de llegada los empujó a desarrollar fuertes lazos de solidaridad étnica (aunque quizás fuera más apropiado decir "paisana"), a fin de amortiguar el impacto y acomodarse mejor a las nuevas condiciones de vida.

Una vez creadas, estas entidades surgidas de la pervivencia de los lazos de paisanaje originados en Galicia, jugaron a su vez un rol fundamental en la consolidación de esos mismos vínculos. A través de las relaciones personales gestadas o reafirmadas en su ámbito, de las conmemoraciones, actividades artísticas (representaciones teatrales, coros, etc.), recreativas (comidas, fiestas campestres y de carnaval, etc.), de sus órganos de expresión, etc., facilitaron la inserción social del inmigrante. Y al intentar reproducir y/o mantener costumbres propias de la sociedad de origen, constituyeron un instrumento evidente de expresión y reforzamiento de la identidad entre los emigrados. Mediante estas dinámicas, repetidas cientos de veces en múltiples años e instituciones, las asociaciones gallegas aglutinaron a los inmigrantes de ese origen, robusteciendo los lazos de solidaridad, los vínculos familiares, e incluso los amorosos. Aunque su grado de influencia no debe ser magnificado, puesto que nunca consiguieron atraer hacia sí más que un número limitado (alrededor de un $25 \%$, en los casos más felices) de los inmigrantes que constituían su clientela potencial (aquéllos que podían llegar a sentirse identificados por su pertenencia al mismo ámbito parroquial, municipal, comarcal, provincial o regional que una determinada socie-

\footnotetext{
9 Sobre su participación en la vida asociativa de la colectividad española genérica, véase FERNÁNDEZ, Alejandro (2007): "Los inmigrantes gallegos y el asociacionismo español de Buenos Aires”, en R. Farías (compilador), Buenos Aires Gallega, pp. 121-34.

${ }_{10}$ Una excelente compilación de trabajos sobre las redes sociales, en BJERG, María y OTERO, Hernán -compiladores- (1995): Inmigración y redes sociales en la Argentina moderna. Tandil: CEMLA - IEHS. Para un resumen de la actuación de las "cadenas" en el caso gallego, véase VÁZQUEZ GONZÁLEZ, Alejandro (2001): "Factores de empuje y condiciones de transporte de Galicia hacia el Río de la Plata”, en X. M. Núñez Seixas (editor), La Galicia Austral, pp. 59-61.

11 Véanse, por ejemplo, PUGA, José (1988): Asi fue nuestro destino. S. 1. [Buenos Aires]: s. ed.; BODELÓN, Julio (1995): Vida azarosa de un emigrante. Lugo: Alvarellos; VARELA, Luis (1996): De Galicia a Buenos Aires -Así es el cuento-. Recuerdos desde el Bar La Cancha. Buenos Aires: Eds. Volpe; RIVAS CANDO; Darío (2008): Darío Rivas Cando. Autobiografia. Buenos Aires: Dunken; SARRIA, Manuel (2009): Relatos de mi vida: un hombre de trabajo. Buenos Aires: Ed. de autor.

12 Para un análisis de los factores que condicionaron el surgimiento del vasto tejido asociativo gallego en Buenos Aires, véase NÚÑEZ SEIXAS, Xosé Manoel (1998): Emigrantes, caciques e indianos. O influxo sociopolítico da emigración transoceánica en Galicia (19001930). Vigo: Xerais, pp. 78-83; ID. (2000), "A parroquia de alén mar: Algunhas notas sobre o asociacionismo local galego en Bos Aires (1904-1936)”, en P. Cagiao Vila (ed.), Semata. Ciencias Sociais e Humanidades, vol 11, pp. 345-49.
} 
dad encarnaba), no cabe duda de que fueron un ámbito de sociabilidad particularmente importante. Ello es evidente (cuando menos hasta la década de 1930) en el caso femenino. Entre las gallegas la inserción laboral se desarrolló de modo predominante en el ámbito del servicio doméstico, de modo que, mientras no se produjo su incorporación a otro tipo de trabajos, el acceso a las sociedades como lugares de contacto externo representó a veces, su única posibilidad de entablar relaciones personales con sujetos de sexo masculino, lo que no dejará de incidir en el comportamiento marcadamente endogámico que desarrolló la primera generación de inmigrantes gallegos. ${ }^{13}$

No es éste el lugar para hacer una descripción pormenorizada del asociacionismo gallego en Buenos Aires. Baste decir que en 1907 surgió el Centro Gallego en Buenos Aires, entidad benéficomutualista que pronto inició un crecimiento espectacular que la llevó a superar a la Asociación Española de Socorros Mutuos de Buenos Aires después de 1930, y a convertirse en la entidad mutualista más grande de la Argentina y de la América hispana. ${ }^{14}$ Pero junto a él, brotaron también a lo largo de los siguientes 53 años varias sociedades regionales (asilos, centros culturales, políticos y otros por el estilo), cuatro centros sociales (uno para cada provincia) y, según un dicho popular, "tantas asociaciones como días hay en el año". Con estas últimas la expansión de las sociedades españolas y gallegas adquirió una nueva dimensión: la microterritorial, sin duda uno de los fenómenos que particularizan a la colectividad gallega dentro del contexto del asociacionismo hispánico. Todo un enjambre de sociedades galle- gas de ámbito parroquial, municipal y comarcal surgió en Buenos Aires entre 1904 y 1936, con un período de máxima intensidad global entre 1907 y 1925, algo bastante lógico, teniendo en cuenta que la parroquia constituía el marco más inmediato de relación social y organización comunitaria de la Galicia rural. Aunque es difícil establecer con precisión su número, puede afirmarse que en dicho período existieron en Buenos Aires no menos de 327 microsociedades. Muchas de ellas conservaron una larga vida, que llega en varios casos hasta el día de hoy. Sin embargo, desde la década de 1930, se advierte la desaparición de algunas y también un proceso de unificación de otras de un mismo ámbito territorial, que se verá acelerado durante y después de la Guerra Civil. Por otra parte, después de 1939 la creación de cuatro centros provinciales (el Centro Orensano-1941-, el Centro Pontevedrés y el Centro Lucense -ambos de 1942-y el Centro Coruñés-1950) refundió a buena parte de estas sociedades..$^{15}$

\section{LA LENGUA}

La actitud frente al idioma propio constituye un importante indicador de los sentimientos de identidad colectiva de un grupo determinado, así como también de su voluntad de asimilación, integración, separación o marginalización en la sociedad receptora. ${ }^{16}$ Para Eva Gugenberger, si la integración supone la incorporación del inmigrante a un Estado con derecho al reconocimiento, autoafirmación y conservación de su identidad, la asimilación, por el contrario, entraña actitudes com-

\footnotetext{
13 Véase, por ejemplo, FARÍAS, Ruy (2008): "Distribución espacial, inserción socioprofesional y conducta matrimonial en un estudio de caso: los gallegos en el Partido de Avellaneda, 1890-1930", en N. De Cristóforis y A. Fernández (editores), Las migraciones españolas a la Argentina. Variaciones regionales (siglos XIX y XX), Buenos Aires: Biblos, pp. 143-7.

${ }^{14}$ En el período 1960-1961 alcanzó la cantidad de 103.711 socios. Vid. CAGIAGO VILA, Pilar y PEÑA SAAVEDRA, Vicente-comisariado (2008): Nós mesmos. Asociacionismo galego na emigración - Asociacionismo gallego en la emigración, S. 1. [Santiago de Compostela], Consello da Cultura Galega, p. 28.

15 Por aquellos años también se creó una nueva institución de carácter benéfico, el Hogar Gallego para Ancianos (1943) ubicado en la localidad de Domselaar (Provincia de Buenos Aires). Véase CAGIAO VILA, Pilar (1999): “A vida cotiá dos emigrantes galegos en América”, en Id. (comp.), Galegos en América e americanos en Galicia, Santiago de Compostela: Xunta de Galicia, pp. 126, 128, 130; NÚÑ̃EZ SEIXAS, Xosé Manoel (1999): “Asociacionismo local y movilización sociopolítica: notas sobre los gallegos en Buenos Aires (18901936), en A. E. Fernández y J. C. Moya (editores), La inmigración española en la Argentina, Buenos Aires: Biblos, pp. 195, 202-8, 211 y 232; ID.: “A parroquia de alén mar", p. 353; MOYA, José C. (2004): Primos y extranjeros. La inmigración española en Buenos Aires, $1850-$ 1930. Buenos Aires: Emecé, 2004, p. 305; FERNÁNDEZ SANTIAGO, Marcelino X. (2001): “Asociacionismo gallego en Buenos Aires (1936-1960), en Núñez Seixas (ed.), La Galicia austral, pp. 187, 193-6.

${ }^{16}$ Sendos análisis sobre la relación entre identidad colectiva y lingüística de los gallegos de Buenos Aires entre comienzos del siglo XX y la década de 1950, en GUGENBERGER, "Identidad, conflicto lingüístico y asimilación" y NÚÑEZ SEIXAS: O inmigrante imaxinario, pp. 209-43.

17 De hecho, en los últimos años ha predominado la utilización del término "integración" en reemplazo de "asimilación", debido a ciertas connotaciones etnocéntricas negativas que el segundo de ellos comenzó a adquirir en el contexto de su empleo acrítico.
} 
pletamente opuestas. ${ }^{17}$ Dentro de ella debe distinguirse entre asimilación como "imitación conciente" y asimilación como "imitación inconsciente" o "identificación". En el primer caso el individuo imita conscientemente la conducta del grupo modelo y se adapta externamente a las normas dominantes, pero guarda una "distancia interna", de modo que su actitud no lo lleva a cuestionarse la pertenencia a su grupo originario ni tampoco su conducta social. En la segunda forma, por el contrario, la identificación incondicional con el grupo dominante implica adoptar su conducta y sus valores sin mantener "distancia interior" alguna, generándose un autoodio por el cual la persona ve a su grupo con los ojos de los "otros" y adopta su punto de vista. Ligada a esta distinción entre imitación e identificación puede diferenciarse, en relación con el proceso por el cual llega a adquirirse una segunda lengua, entre una motivación instrumental y otra integradora: el aprendizaje instrumental de la segunda lengua nace de la necesidad de comunicación y tiene por lo tanto una orientación predominantemente práctica; en la motivación integradora, por el contrario, el hablante de una lengua tipo " $B$ " quiere integrarse en el grupo de la lengua " $A$ ", hablar como él por razones más ligadas al status, llegando incluso, al punto de abandonar su acento $\mathrm{u}$ ocultar su origen lingüístico. ${ }^{18}$

En el caso que nos ocupa, las diferentes formas de asimilación se combinaron con las poco favorables pautas imperantes en la sociedad argentina, donde la oleada migratoria de las primeras tres décadas del siglo XX reactivó los tópicos despectivos hacia los gallegos heredados desde los tiempos de la Colonia (ingenuos, toscos, incultos, etc.). Éstos cobraron una nueva capacidad de verosimilitud en virtud de

esa nova "invasión" de inmigrantes [...] [de] escasa calificación e vagaxe formativa e analfabetos nunha proporción apreciable [o] poco competentes en castelán, algo que para os observadores arxentinos non sempre era doado de entender: que os inmigrantes galegos falasen incorrectamente o castelán non por ignorancia, senon por posuiren outra lingua materna., 19
Así, al llegar a Buenos Aires, los inmigrantes galaicos se enfrentaron a la necesidad de adaptarse a las normas y pautas de una sociedad distinta, cuyo idioma oficial es el castellano, la misma lengua dominante en Galicia, de donde muchos llegaban siendo monolingües en gallego, pero cargando el estigma de hablar una lengua que era sinónimo de tonto e ignorante. De este modo, en su proceso de incorporación a la sociedad porteña acabaron por entrelazarse la motivación instrumental y la integradora. En su vida laboral y en sus contactos fuera del núcleo familiar tienen que desenvolverse en castellano, pero a esta necesidad práctica se suman factores de carácter psicológico: el hecho de verse a sí mismos como miembros de un estrato social más bien bajo y con un pobre nivel de instrucción escolar, y el fuerte deseo de superación, de ascender socialmente y de brindar a sus hijos un futuro mejor, son factores que también fomentan la disposición a asimilarse a una sociedad receptora en la que su idioma no les "sirve" socialmente. Aunque imposibles de cuantificar, es un hecho que detrás de conductas como la del compostelano Manuel Iglesias Raíces que, a poco de llegar su esposa e hijos a Buenos Aires en 1953, les prohibió el empleo del idioma gallego (aún en el ámbito familiar), se halla el afán de integrarse y de integrar a los suyos. ${ }^{20}$

Aunque no puede establecerse una relación de causalidad, según la cual del hecho de no continuar practicando uno o varios aspectos característicos del modo de vida originario se deduzca automáticamente la pérdida definitiva de la identidad étnica, es indudable que

lo que se observa frecuentemente en el caso de hablantes de lenguas minoritarias desprestigiadas por la sociedad dominante es que se confiere un valor muy alto en el ámbito emocional a la lengua materna, mientras que al mismo tiempo se le atribuye un bajo valor social. La [...] lengua materna [...] constituye un lazo emocional con la tierra natal y es capaz de evocar los paisajes y las vivencias de la niñez. Pero como no se le otorga mucha importancia en la lucha por aumentar el propio prestigio social y mejorar el status económico, muchos hablantes tra-

\footnotetext{
18 Véase, GUGENBERGER: "Identidad, conflicto lingüístico y asimilación”, pp. 256-8.

19 NÚÑEZ SEIXAS: O inmigrante imaxinario, pp. 43-4. Sobre la imagen de los gallegos en la Argentina, véase también LOJO, María Rosa (directora), GUIDOTTI DE SÁNCHEZ, Marina y FARÍAS, Ruy (2008): Los "gallegos" en el imaginario argentino. Literatura, sainete, prensa. A Coruña/Vigo: Fundación Pedro Barrié de la Maza.

${ }_{20}$ Vid. IGLESIAS LÓPEZ, María Rosa (2007): “Con las raíces al aire: La experiencia de las emigrantes gallegas a través de nueve protagonistas", en R. Farías (compilador), Buenos Aires Gallega, p. 172.
} 
tan de adaptarse a las normas reinantes renunciando a $[\ldots]\left[\right.$ ella]. ${ }^{21}$

Durante las primeras décadas del siglo XX las elites intelectuales y periodísticas de la colectividad gallega porteña más comprometidas con la causa del mantenimiento del idioma y la identidad galaica entre sus paisanos de Buenos Aires, solían expresarse en términos catastrofistas acerca de la acelerada decadencia del empleo del idioma gallego entre los emigrantes. No obstante los sombríos comentarios de sus observadores contemporáneos, y teniendo en cuenta que tras superar la desfavorable coyuntura de la Primera Guerra Mundial se asiste, entre 1920 y 1930, a una nueva llegada masiva de inmigrantes de origen rural y mayoritariamente monolingües en gallego, resulta factible sostener que aquel idioma continuó vivo entre los emigrantes. Pero ¿de qué modo?

Puede suponerse que seguía siendo empleado de acuerdo con el código de "lengua de solidaridad" que imperaba en el medio rural gallego, de modo que continuó hablándose en el seno de las redes sociales informales y familiares, en las fiestas y, naturalmente, en los momentos de esparcimiento en los centros y sociedades étnicas, y toda vez que los inmigrantes tenían ocasión de reunirse. Sin embargo, su uso público "formal" debió ser muy reducido, al igual que en la comunicación epistolar. A pesar de su alta tasa de endogamia, la transmisión intergeneracional de la lengua en las familias gallegas se reducía drásticamente una vez que los inmigrantes se asentaban definitivamente o por un largo período de tiempo en su punto de destino. De este modo, el gallego permaneció como idioma de comunicación informal entre los emigrantes de primera generación, pero se difuminó de modo irremisible en la segunda cuando la instalación en el país se convertía en definitiva o de larga duración. ${ }^{22}$ Pero si ese era el "cuadro de situación" en la esfera privada, el escenario no se presentaba mejor al pasar a la pública o institucional. Con anterioridad a la década de 1920, el habla galaica se halla prácticamente ausente de la documentación interna y de las memorias editadas por las asociaciones de emigrantes, y rara vez era empleada en público en los actos de la colectividad inmigrante: su uso en circunstancias "formales" causaba extrañeza y la reacción de la elite no solía ser positiva cuando el empleo del mismo superaba las funciones secundarias, "permitidas" y más o menos cómico-festivas. La diglosia funcional asociaba y limitaba el uso escrito del gallego a la gastronomía y diversión, junto con la evocación de la comarca de origen. ${ }^{23}$ Es cierto que frente a esta situación los sectores nacionalistas galaico-porteños asumieron de modo decidido la defensa de su oficialidad en las instituciones de la colectividad (sobre todo en el caso de la militante Federación de Sociedades Gallegas). No obstante, ello no fue obstáculo para que persistieran fuertes reservas, cuando no hondos prejuicios, frente a su uso público entre buena parte de las elites de la colectividad.

\footnotetext{
${ }^{21}$ GUGENBERGER, "Identidad, conflicto lingüístico y asimilación”, p. 272. Para la misma autora (pp. 264-6), sin bien la lengua ocupa un lugar especial en el conjunto de los elementos que conforman la identidad étnica, no constituiría un elemento indispensable de dicha identidad.

${ }_{22}$ Así, conforme los emigrantes conseguían establecerse de modo independiente y experimentaban un ascenso social disminuía el uso del gallego, que se reservaba para contextos informales de familiaridad y ocio, algo a lo que sin duda contribuía aquel estigma de inferioridad asociado a ese idioma. Es, por poner un ejemplo, lo que se desprende de 18 entrevistas realizadas por el autor a otros tantos emigrantes del municipio pontevedrés de Catoira en la Argentina.

${ }^{23}$ Así, por ejemplo, el Boletín Oficial del Centro Gallego de Buenos Aires (1913-1925) prácticamente no utiliza el gallego más que en las muy puntuales situaciones en las que se quería dar un carácter marcadamente étnico a algún texto, por lo general referido a alguna festividad de corte popular. Independientemente de la imagen idealizada que contiene, resulta un buen exponente de ello la siguiente convocatoria a las romerías que la institución organizó en marzo de 1920: "Las romerías a celebrarse este año en el pintoresco "Pabellón de las Rosas" [...] serán de un marcado sabor regional y del colorido que más semejanza tenga al de las tradicionales de nuestra tierra meiga [...]. No faltará, pues, la aldea gallega con su ermita contigua [...] evocadora de aquellos que duermen al arrullo de múltiples regatos, escuchando atentamente el rumor quejumbroso de los pinos y participando de la fresca sombra y del abrigo de sus carballeiras; ni el mesón, con su indispensable ramo de loureiro en la puerta, indicador de que allí se come a la usanza del país y se bebe viño do Ribeiro e da Ulla por cuncas, mientras un fato de petrucios sentados en tallos y alrededor de una rústica mesa, cuentan como les fue en la feria o romería de donde regresan. Para los amantes de la danza, además de las dulzamas y murgas que amenizaran los bailes de agarradiño, ocupará su puesto de honor la gaita, luciendo su dourado o colorado fleque en el roncón [...]. La muñeira y otros bailes típicos de la región gallega, formarán parte de las romerías de nuestro Centro, en las cuales los concurrentes tendrán también puestos de rosquillas y resolio, y, además de las suculentas y bien condimentadas comidas del mesón, entre las que figurara el sabroso pulpo, hallaran lugares adecuados para tender los blancos manteles sobre el verde césped y merendar como en nuestras romaxes.” “¡A las romerías! ¡Todos al Pabellón de las Rosas, a divertirse!", en Boletín Oficial del Centro Gallego de Buenos Aires [BOCG], n 87, marzo 1920, pp. 3-4. (Las bastardillas pertenecen al texto original).
} 


\section{LAALIMENTACIÓN}

La alimentación constituye un elemento clave en el ejercicio de la sociabilidad entre aquellos que emigran. Dado que en líneas generales los gallegos se integraron en la dinámica socioeconómica de Buenos Aires sin mayores dificultades (excepción hecha a los ya aludidos problemas con el idioma), podría pensarse que, transcurridos muchos años desde su llegada, serían absorbidos por el medio y perderían toda identificación con su lugar de origen. Sin embargo, como sucediera con la relación entre sus formas de sociabilidad y las instituciones que fundaron en esta ciudad, las cosas no siempre fueron así. De la sociedad porteña los gallegos adoptaron nuevas pautas de alimentación, ya fueran éstas criollas o propias de otras colectividades inmigrantes. Pero esta adopción se combinó con la conservación de muchas de sus propias tradiciones culinarias, generalmente por costumbre, pero también como refuerzo de su identidad de origen. En el período examinado existen ciertas preferencias gastronómicas que los vinculan con su tierra de origen y que, de acuerdo con las diferentes posibilidades económicas del emigrante, fueron una forma de recrear Galicia en el Río de la Plata. Indudablemente, la evaluación de la reproducción, conservación, hibridación o abandono de la gastronomía gallega en el ámbito privado porteño es sumamente difícil, siendo necesario apelar a una amplia cantidad de fuentes orales, prosopográficas y literarias que (además de ser por ahora francamente insuficientes) exceden las posibilidades del presente trabajo. No obstante ello, podemos hacer algunas afirmaciones básicas.

Una vez en Buenos Aires, al mismo tiempo que echaron en falta productos de su tierra, los gallegos se encontraron con otros desconocidos en su lugar de origen, o a los que no tenían allí fácil acceso: nuevas frutas, hortalizas y verduras pero también (y sobre todo) la carne vacuna. Los hogares de aquellos inmigrantes que vivieron en Galicia la escasez de productos adaptaron su cocina a esta nueva realidad, y en la comida de todos los días (como en tantos otros campos) acabaron por generar una especie de sincretismo entre sus costumbres culinarias y las que encontraron en la sociedad receptora. No obstante, para quienes estaban en condiciones de pagarlos, existió siempre una no despreciable oferta de tiendas de importación y comercialización (generalmente regenteadas por gallegos u españoles), que ofrecían a la venta una multitud de productos de Galicia y de España. ${ }^{24} \mathrm{La}$ gran proliferación de este tipo de comercios (cuya distribución espacial se corresponde notablemente con la ubicación geográfica de las áreas de asentamiento típicas de los gallegos en Buenos Aires) es un indicador de la existencia de una demanda ávida de esos productos o, cuando menos, de la percepción por parte de los productores o comercializadores de un gusto y/o clientela potencial en el seno de la colectividad gallega. Además, existieron en Buenos Aires numerosos locales en donde se vendían, listos para consumir, platos típicos de la dieta gallega. ${ }^{25}$

Más allá de la existencia de esta oferta, es indudable cierta pervivencia de la cocina gallega en el ámbito rioplatense. Cristina Samuelle Lamela señala que allí continúa preparándose la empanada, el cocido, el caldo, etc. ${ }^{26}$ Otro plato típico que pervivió en la emigración porteña fueron las sardinas con cachelos, y también la preparación del pescado y el pulpo al estilo de Galicia. A esta tradición se suman además dulces como las filloas, la rosca, el arroz con leche, los churros y la tarta de Santiago. ${ }^{27}$ Por su parte, Neira Vilas sostiene que

os paisanos que tiñan casa de seu, moitas veces dábanlle un aquel evocador no feitio da porta de entrada, na cheminea e nalgunha lareira anexa, con burro, gramalleira, trapias, filloeiro e algunha pota de ferro $[. .$.$] soian ter forno e cocian o pan, frecuen-$ temente de millo cun algo de centeno ou de trigo, [e incluso] algúns pedían semente a Galicia e nas hortas cutivaban patacas, verzas, cebolas ou nabos de determinadas variedades [;] houbo quen fixo levar nabina de toxo para o xardín, e ovos galados co

${ }^{24}$ Véase, por ejemplo, El Eco de Galicia [EEG], VIII: 281, 10.8.1899, p. 12; EEG, IX: 299, 10.2.1900, pp. 12, 15; EEG, X: 339, 20.3.1901, p. 9; EEG, XVII: 593, 10.4.1908, pp. 9, 12; BOCG, n 152 , julio 1925, p. 14; Galicia. Revista del Centro Gallego de Buenos Aires [GA], $\mathrm{n}^{\circ}$ 278, marzo 1936, p. 47; BOCG, $\mathrm{n}^{\circ}$ 90, junio 1920, p. 27; GA, nº 215, noviembre 1930, p. 15; GA, n 276, enero 1936, p. 20; BOCG, $n^{\circ} 151$, junio 1925, p. 14; GA, nº 166, septiembre 1926, p. 29; GA, nº 279, abril 1936, p. 40.

25 Vid., por ejemplo, Galicia. Portavoz de la Federación de Sociedades Gallegas, Buenos Aires, nº 666, 16.3.1940, 2-3.

${ }^{26}$ Ciertos testimonios indican, además, que hubo incluso algunos gallegos poseedores de pequeñas parcelas de tierra en la que cultivaban las tradicionales berzas, componente esencial del caldo gallego.

27 Véase SAMUELLE LAMELA, Cristina (2000): La emigración gallega al Río de la Plata. Santiago de Compostela: Xunta de Galicia, pp. 198-204. 
propósito de criar certas castes de galinas [y] había en Buenos Aires rosquilleiras, unha delas moi popular no barrio de Balvanera; outras vendían empanadas en cachos ou porcións $[\ldots] .{ }^{28}$

Sin embargo, como en parte ya señalamos, dado que en Buenos Aires confluyeron gentes de muy distintas latitudes y naciones, es lógico que los gallegos acabaran por incorporar a sus gustos culinarios platos llegados junto con las tradiciones de otros pueblos y, siendo el italiano el más numeroso de todos los grupos estatales arribados a la Argentina, no sorprenderá que la influencia de su cocina se hiciera sentir con fuerza. Esto es particularmente cierto en lo que hace a las pastas y las pizzas que, como describiera con su habitual perspicacia e ironía Antonio Pérez-Prado, muchas familias gallegas comenzaron a comer por influjo de su nueva nuera italiana o hija de familia italiana. ${ }^{29}$ Por otra parte, los gallegos y sus descendientes añadieron igualmente a su dieta comidas típicas de otros pueblos españoles.

En cualquier caso, siempre que se quiere celebrar algo, ya sea a nivel personal o institucional, se hace por medio de la elaboración de una comida: reunirse para comer es un hecho muy común en los diversos medios en los que se mueven los emigrantes. Lógicamente, es mucho más sencillo para el investigador seguir la evolución de estas comidas en su faz pública. En ellas, el ámbito de la reunión, la composición de los alimentos, su presentación, el género y el número de los convidados variará dependiendo del status del espacio de socialización elegido y la clase social de quienes componen, convocan u organizan la reunión. En tales ocasiones la comida ingerida es preferentemente la típica, aunque no es infrecuente la aparición en el menú de platos rioplatenses. Entre la élite de la colectividad se reproducen los patrones más típicos de una alimentación burguesa de clase alta, con su estilización de las formas, la variedad de platos más o menos refinados y, en las décadas iniciales del siglo XX (aunque no sólo en ellas), con una exclusión casi absoluta de la mujer. Así, por ejemplo, el homenaje tributado en 1913 por la
Comisión Directiva del Centro Gallego de Buenos Aires a Juan A. Alsina (ex-director de la Dirección Nacional de Migraciones, y autor de un libro de viajes en el que se ensalzaba a Galicia), convoca a lo más granado de la colectividad (masculina) para una cena en la que se consumen productos considerados delicados, y a los que se pretende dar un "toque" mediante el empleo de algunos nombres de localidades gallegas (aunque castellanizados, a fin de salvaguardar el "buen gusto"):

El menú muy bien servido por la Rotisserie Domenech de la calle Esmeralda 48 se componía de los siguientes platos: Fiambres: surtidos, sopa de Nabizas. Pescado: Mero "Centro Gallego". Entradas: Pastelillos de "La Toja", Pollo a la Criolla. Legumbres: Espárragos "regionales". Postres: Crema Nevada "J. A. Alsina", Torta del "Porriño", Ensalada de Frutas "España". Vinos: Blanco. "Bodegas Gallegas", Tinto: "Bodegas Gallegas", "Marqués de Riscal", Jeres (sic), Champagne “Ayala". Café, Licores y Cigarros. [...]. Al descorcharse el champagne, $[\ldots] .{ }^{30}$

De este modo, junto a lo ya dicho a propósito del papel de las instituciones como ámbitos de socialización, debe ponerse de relieve el rol que también jugaron como mecanismos de expresión de identidad culinaria, debido a su vocación de reproducir pautas y costumbres propias de la sociedad de origen. Ello puede observarse en acontecimientos tales como almuerzos, cenas, fiestas, actos de entretenimiento, pic-nics, en los que se consumían platos típicos ya mencionados (caldo gallego, sardinas con cachelos, cocido, etc.), junto con el bacalao con patatas o el vino (cuya procedencia quizás no era gallega, pero que solía tomarse en las tradicionales cuncas), mientras intentaban imitarse los ambientes típicos de la taberna o el paisaje campesino, con su hórreo, su cruceiro y su iglesia. ${ }^{31}$ Dentro del espectro de estas reuniones de corte popular, merecen una llamada aparte los picnics y las romerías, sean estas últimas al aire libre o bajo techo. Es en este tipo de convivencias donde, para Pilar Cagiao Vila, se reflejaría cierta armoniosa mixtura de las costumbres alimentarias

28 NEIRA VILAS: A cultura galega, pp. 35-6.

29 Véase PÉREZ-PRADO: Los gallegos y Buenos Aires, p. 250.

30 "En honor de D. Juan A. Alsina. Un banquete memorable", en BOCG, no 3, marzo 1913, pp. 1-7, 9,11,13,15

31 Véase, por ejemplo, Galicia. Publicación semanal de la Federación de Sociedades Gallegas [GAL], $\mathrm{n}^{\circ}$ 636, 20.8.1939, p. 5; GAL, ${ }^{\circ}$ 639, 9.9.1939, p. 6; GAL, n⿳ 653, 16.12.1939, p. 12; GAL, n 902, 28.4.1945; GAL, n 876, 21.10.1944; "Nuestras próximas romerías. A beneficio del hospital-sanatorio", BOCG, n 86, febrero 1920, p. 3; “¡A las romerías! ¡Todos al "Pabellón de las Rosas”, a divertirse!”, BOCG, n 87, marzo 1920, pp. 3-4; "Nuestras romerías", BOCG, n 88, abril 1920, p. 7. 
de los inmigrantes gallegos con los nuevos hábitos adquiridos. ${ }^{32}$ En ellas, además, la etiqueta y las formas pasan a un oscuro segundo plano dejando lugar a una expansión sino del espíritu, al menos sí de los sentidos. Junto a ello, estas reuniones y el ámbito en el que se desarrollan tienen la particularidad de incluir la participación de las mujeres y los niños, cuya presencia se hallaba limitada, precisamente, a aquellas reuniones evocadoras de la sociedad de partida o de carácter cómico-festivas. Quiénes y cómo participaban en un convite no es, ciertamente, un detalle menor.

\section{A MODO DE CONCLUSIÓN}

Cuál fue la relación y la actitud que cada gallego de primera, segunda o tercera generación experimentó en el pasado respecto a la sociabilidad, costumbres culinarias y lengua del grupo es algo que escapa a nuestra posibilidad de análisis. Lo que sigue representa apenas una valoración general que nuevos y mayores estudios deberán confirmar, modificar o refutar.

A lo largo de las primeras seis décadas del siglo $\mathrm{XX}$, los inmigrantes gallegos se integraron en la dinámica socioeconómica de la sociedad porteña sin mayores dificultades, pero manteniendo en mayor o menor grado ciertos rasgos y preferencias característicos que los identificaban con su lugar de origen.
Más allá de la multitud de ejemplos que en uno $\mathrm{u}$ otro sentido pueden esgrimirse, el ámbito relacional del gallego parece haberse ceñido en general a la familia y las relaciones personales conexas. Como medio de vinculación social más amplio, en un número apreciable (aunque siempre minoritario) buscaron unirse a sus paisanos, desarrollando a veces fuertes lazos de solidaridad y sistemas formales e informales de ayuda mutua, tanto étnica como panhispánica. En ese sentido, se operó cierta "apertura" en unas personas que, después de todo, procedían del seno de una sociedad en la que la vecindad y el parentesco tenían una importancia superlativa frente a la que se otorgaba a las "relaciones de afinidad electiva". A su vez, estas asociaciones voluntarias jugaron (y algunas continúan haciéndolo) un rol fundamental en la consolidación y pervivencia de los mismos lazos de paisanaje que motorizaron su aparición.

Del mismo modo, existieron y existen aún ciertas preferencias culinarias que, de modo cotidiano o en fechas señaladas, los vinculaban con su tierra natal y recrean Galicia en Buenos Aires.

Mientras tanto, la lengua propia del país parece haber tenido mucha menor fortuna. Se mantuvo al nivel familiar o con los paisanos más allegados como segunda lengua de relación, pero no gozó de gran estimación en el nivel formal de las instituciones ni se transmitió (salvo casos excepcionales) a las nuevas generaciones.

32 Véase CAGIAO VILA: “A vida cotiá”, p. 132. 